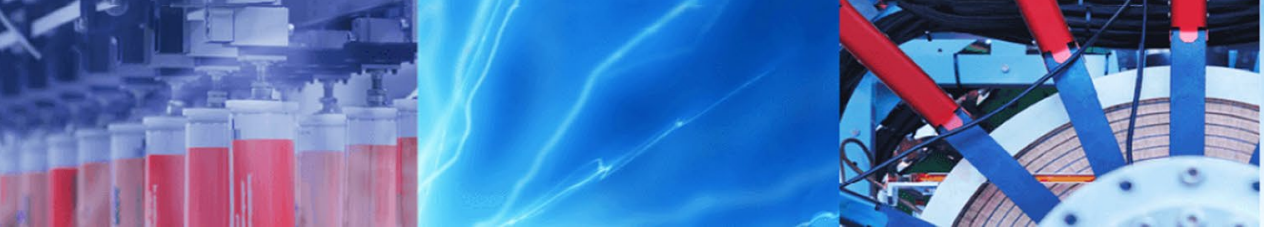

Research Article

\title{
Study on the application mechanism and mechanics of steel slag in composite cementitious materials
}

\author{
Zhimin Chen ${ }^{1} \cdot \mathrm{Kun} \mathrm{Tu}^{1} \cdot \mathrm{Rui}_{\mathrm{Li}}{ }^{1} \cdot$ Jiaxiang $\mathrm{Liu}^{1}$ (I)
}

Received: 11 July 2020 / Accepted: 7 October 2020 / Published online: 16 October 2020

(c) Springer Nature Switzerland AG 2020

\begin{abstract}
Enormous demand and production for cement and concrete lead to a sharp increase in carbon dioxide emissions, and alternatives to cement are urgently needed to produce green cement and concrete. This paper is aimed at exploring the feasibility of using steel slag (SS) and granulated blast furnace slag (GBFS) to prepare cementitious materials. Mineral phases of SS are determined and observed by X-ray diffraction and backscattered electron microscopy. By measuring the compressive strength of mortar samples, the composite effect of SS-GBFS is analyzed and compared. Results show that SS can replace cement by $10 \%-30 \%$, and the long-term strength of the prepared binary cementitious material is higher than that of cement. SS and GBFS can replace up to $50 \%$ of the cement. The strength of SS-GBFA-C ternary cementitious material is higher than that of SS-C, SS and GBFS promote mutually in cementitious materials.
\end{abstract}

Keywords Steel slag · Granulated blast furnace slag · Compressive strength · Supplementary cementitious material

\section{Introduction}

Portland cement production is an energy-intensive consumption process, and the cement industry accounts for $5 \%-8 \%$ of global carbon dioxide emissions annually [1-4]. The rapid development of China's construction, road and bridge construction industry leads to a great demand for concrete and cement. China's cement yield has been ranked first in the world for exceeding 20 years [5]; engineers and scientists have been searching for secondary raw materials that could substitute cement and advance the properties of cement. On the one hand, to reduce depletion of raw materials for cement production is of major importance for the prospect of developing sustainable construction materials and conserving natural resources. On the other hand, reducing the consumptions of heat and electricity to obtain these materials could indirectly curtail carbon dioxide emissions [6].
In recent years, cement and concrete composites have developed rapidly; cement mixtures containing different kinds of supplementary cementitious materials (SCMs) effectually reduce the dosage of cement powder. As stated by [7-10], SCMs can be categorized into industrial wastes, such as fly ash, silica fume, ground granulated blast furnace slag, agriculture wastes and aquaculture wastes. The application of SCMs in practical building materials shrinks the use of cement and reduces the emission of carbon dioxide.

Steel slag (SS) and granulated blast furnace slag (GBFS) are by-products of the production process of iron and steel industry, accounting for $30 \%$ of the total industrial byproducts in China [11]. The chemical and mineral compositions of SS and GBFS are approximating to cement, and researches indicated that SS and GBFS could be used as aggregates, SCMs and binder in the cement and concrete industry [1]. GBFS has been widely used in cement and concrete as SCMs. Nevertheless, the effective utilization

Jiaxiang Liu, ljxpost@263.net | ${ }^{1}$ Beijing Key Laboratory of Electrochemical Process and Technology for Materials, Beijing University of Chemical Technology, Beijing 100029, China. 
rate of SS is low, only about $22 \%$, because of its low hydration property and poor soundness [12]. The output of SS accounts for $15-20 \%$ by mass of the total output of crude steel [13]. The accumulation of SS not only is a waste of resources, but also pollute to the environment $[14,15]$.

Reddy et al. [16] detected that the strength of waterquenched SS as hydraulic cementitious materials is up to $42.7 \mathrm{MPa}$ after 28 days. Papayianni and Anastasiou [17] studied the replacement of cement with 30\% SS and 50\% FA as cementitious materials, and the concrete made by replacing some coarse aggregate with SS has higher compressive strength (>70 MPa), higher abrasion resistance and fracture toughness than ordinary cement concrete. Sheen et al. [18] studied the properties of green concrete obtained by replacing coarse aggregate and fine aggregate with SS; results show that the compressive strength of concrete made from $100 \%$ SS replacing fine aggregate is higher than that of ordinary concrete.

The wide application and short supply of GBFS have brought new challenges to the cement industry. On the contrary, the low utilization rate of SS has not been solved so far. In order to improve the utilization of SS and reduce the load on the cement industry, this paper aimed at mixing GBFS and SS to cement, preparing composite cementitious materials. The interaction among SS, GBFS and cement was studied by characterizing the hydration properties of the material. At the same time, the effect of raw material ratio on the mechanical properties of composite cementitious materials is explored to determine the optimal mixing ratio between SS and GBFS in cement.

\section{Materials and methods}

\subsection{Materials}

SS produced by Xinyu Iron And Steel Co. Ltd obtained by crushing, removing iron, grinding and sifting has a density of $3.91 \mathrm{~g} / \mathrm{cm}^{3}$ and a specific surface area of $469 \mathrm{~m}^{2} / \mathrm{kg}$. Industrial-grade GBFS powder is of a density of $2.90 \mathrm{~g} / \mathrm{cm}^{3}$ and a specific surface area of $354 \mathrm{~m}^{2} / \mathrm{kg}$. Tap water and ISO standard sand were used to prepare mortar. Table 1 shows the main chemical composition of C (cement), SS and GBFS in this research.

\subsection{Methods}

\subsubsection{Determination and observation of mineral phases}

$X$-ray diffraction was used to determine the chemical and mineral compositions of SS. Mineral phases of SS were observed and identified by backscattered electron (BSE) imaging technique and the element content of the surface microregion was analyzed by energy-dispersive X-ray spectroscopy (EDX). The surface morphology of SS-C after hydration was analyzed by scanning electron microscope (SEM). TG was used to analyze the hydration mechanism of composite cementitious materials.

\subsubsection{Strength test of mortar specimens}

The proportion of SS and GBFS mixed with cement is shown in Table 2. Mortar specimens were prepared in the $40 \mathrm{~mm} \times 40 \mathrm{~mm} \times 160 \mathrm{~mm}$ mold. After molding, put into standard constant temperature and humidity curing box (YH-40B) for $24 \mathrm{~h}$ and then demold, curing at BWJ-1 automatic cement curing water tank. Curing time was from the time of specimen molding to the time of testing the flexural and compressive strength, which was $3 \mathrm{~d}, 7 \mathrm{~d}$ and $28 \mathrm{~d}$, respectively, and the time error was less than $1 \mathrm{~h}$. During the experiment, the temperature was controlled at $20^{\circ} \mathrm{C} \pm 1{ }^{\circ} \mathrm{C}$, the relative humidity was more than $50 \%$, and the humidity of standard curing box was more than $90 \%$.

\section{Results and discussion}

\subsection{Mineral phase in SS}

Figure 1 shows the X-ray diffraction pattern of SS powder. The results show that the minerals in SS mainly included tricalcium silicate $\left(C_{3} S\right)$, ferroaluminum-calcium phase $\left(\mathrm{Ca}_{2}[\mathrm{Fe}, \mathrm{Al}]_{2} \mathrm{O}_{5}\right)$, calcium carbonate $\left(\mathrm{CaCO}_{3}\right)$, RO phase ( $\mathrm{MgO}, \mathrm{FeO}$ and $\mathrm{MnO}$ solid solution), free calcium oxide ( $\mathrm{f}-\mathrm{CaO}$ ), calcium hydroxide $(\mathrm{CH})$ and dicalcium silicate $\left(C_{2} S\right) . C_{3} S$ and $C_{2} S$ in $S S$ were the main sources of cementitious properties. However, $\mathrm{C}_{3} \mathrm{~S}$ and $\mathrm{C}_{2} \mathrm{~S}$ in $\mathrm{SS}$ are formed by melting at $1650{ }^{\circ} \mathrm{C}$ at high temperature, resulting in
Table 1 Chemical composition of raw materials

\begin{tabular}{llrrrrrrrrr}
\hline Raw materials & \multicolumn{1}{l}{ Mass percentage (\%) } \\
\cline { 2 - 9 } & $\mathrm{SiO}_{2}$ & $\mathrm{Al}_{2} \mathrm{O}_{3}$ & $\mathrm{Fe}_{2} \mathrm{O}_{3}$ & $\mathrm{CaO}$ & $\mathrm{MgO}$ & $\mathrm{FeO}$ & $\mathrm{Na}_{2} \mathrm{O}$ & $\mathrm{SO}_{3}$ & $\mathrm{f}-\mathrm{CaO}$ & LOI \\
\hline $\mathrm{C}$ & 21.78 & 5.17 & 0.49 & 65.21 & 4.43 & - & 0.13 & 2.79 & 0.86 & 1.33 \\
$\mathrm{SS}$ & 12.86 & 1.70 & 13.09 & 54.64 & 8.36 & 9.35 & - & - & 2.39 & 1.71 \\
GBFS & 31.98 & 16.74 & 0.75 & 38.49 & 10.11 & - & - & 1.93 & 0.43 & 0.22 \\
\hline
\end{tabular}


Table 2 Proportion of mortar samples

\begin{tabular}{llllllll}
\hline Samples & Cement/\% & SS/\% & GBFS/\% & Samples & Cement/\% & SS/\% & GBFS/\% \\
\hline S0 & 100 & 0 & - & S40G10 & 50 & 40 & 10 \\
S10 & 90 & 10 & - & S35G15 & 50 & 35 & 15 \\
S20 & 80 & 20 & - & S30G20 & 50 & 30 & 20 \\
S30 & 70 & 30 & - & S25G25 & 50 & 25 & 25 \\
S40 & 60 & 40 & - & S20G30 & 50 & 20 & 30 \\
S50 & 50 & 50 & - & S48G12 & 40 & 48 & 12 \\
S60 & 40 & 60 & - & S42G18 & 40 & 42 & 18 \\
S32G8 & 60 & 32 & 8 & S36G24 & 40 & 36 & 24 \\
S28G12 & 60 & 28 & 12 & S30G30 & 40 & 30 & 30 \\
S24G16 & 60 & 24 & 16 & S24G36 & 40 & 24 & 36 \\
S20G20 & 60 & 20 & 20 & & & & \\
S16G24 & 60 & 16 & 24 & & & & \\
\hline
\end{tabular}

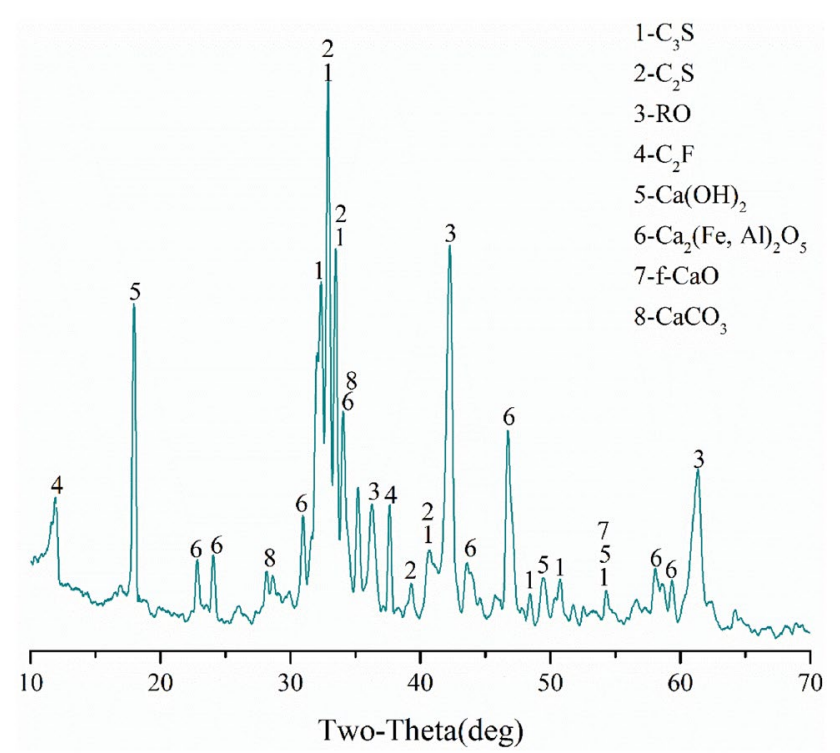

Fig. 1 X-ray diffraction pattern of SS

many vitreous bodies, relatively dense structure and low cementitious activity [19].

Figure 2 presents the BSE images of steel slag, and the EDX analysis results are listed in Table 3. The minerals in SS were mainly silicate including $C_{3} S$ and $C_{2} S$, RO phase, ferroaluminum-calcium phase and free calcium oxide, which was basically consistent with $\mathrm{X}$-ray diffraction analysis as shown in Fig. 1. RO phase was generally considered to have no hydration activity [5], but accounts for 20-30\% in SS, resulting in lower relative content of cementitious active substances in SS than GBFS and cement. $\mathrm{F}-\mathrm{CaO}$ is the main factor leading to poor volume stability of SS [20, 21].

\subsection{Binary cementitious material}

\subsubsection{Strength analyses}

Figure 3 shows the compressive strength of SS-C cementitious material with different SS contents. The early strength (3d) of the mortar sample prepared by SS instead of part of cement was lower than that of pure cement. With the increase in the SS content, the early strength of the composite cementitious material decreased gradually, and the strength of the medium (7d) and long-term (28d) increased first and then decreased. The binary cementitious material with $10 \%$ SS content has the best mechanical properties, and the compressive strength of $7 \mathrm{~d}$ and $28 \mathrm{~d}$ is higher than that of pure cement. The change of the
Fig. 2 BSE images of various mineral phases in SS
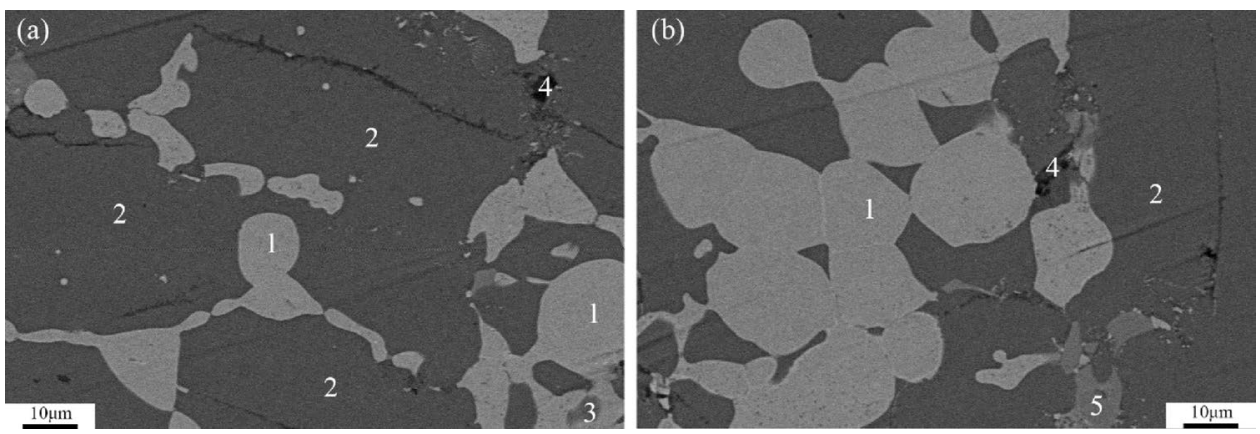
Table 3 EDX analysis results of various mineral phases in SS

\begin{tabular}{llllrrrr}
\hline Selected areas & \multicolumn{7}{l}{ Atomic percentage (\%) } \\
\cline { 2 - 7 } & $\mathrm{O}$ & $\mathrm{Mg}$ & $\mathrm{Al}$ & $\mathrm{Ca}$ & $\mathrm{Si}$ & $\mathrm{Mn}$ & $\mathrm{Fe}$ \\
\hline 1 & 54.89 & 17.01 & - & 0.27 & - & 3.41 & 24.43 \\
2 & 62.36 & 0.48 & - & 24.57 & 12.42 & & 0.26 \\
3 & 59.44 & 4.46 & - & 16.83 & 10.06 & 1.14 & 8.08 \\
4 & 60.13 & 1.56 & 5.21 & 9.58 & 4.76 & 0.68 & 5.26 \\
5 & 67.02 & 0.43 & 4.40 & 20.88 & 2.89 & - & 4.38 \\
\hline
\end{tabular}

Fig. 3 Compressive strength (a) and flexural strength (b) of SS-C binary composites

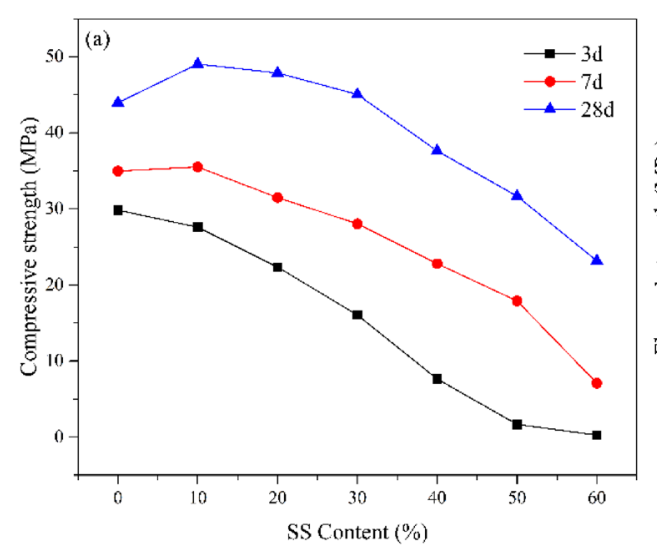

flexural strength of SS-C cementitious material has a similar pattern.

When the content of SS was higher than $30 \%$, the compressive strength of the sample decreased obviously, which limits the use of SS in large quantities.

\subsubsection{Activity index}

Figure 4 presents the activity index of $7 d$ and $28 d$ of the mortar samples with different SS contents. The activity index of SS-C binary composites decreased with the addition of SS. When SS was added with no more than $30 \%$, the activity index of SS-C composite powder for $7 \mathrm{~d}$ was above $80 \%$, and that for $28 \mathrm{~d}$ was above $100 \%$. The high activity index of composite cementitious materials in the early hydration age benefited from the filler effect of SS in cement.

\subsection{Ternary cementitious material}

Figure 5 shows the compressive strength of ternary cementitious material. As the cement content decreased, the compressive strength of the samples decreased significantly. When the amount of cement was constant, the strength of cementitious materials increased with the increase in the GBFS content. SS and GBFS can replace 50\% cement at most. When cement content in ternary cementitious material was $40 \%$, the strength of the paste was lower than that of cement. By comparing the compressive

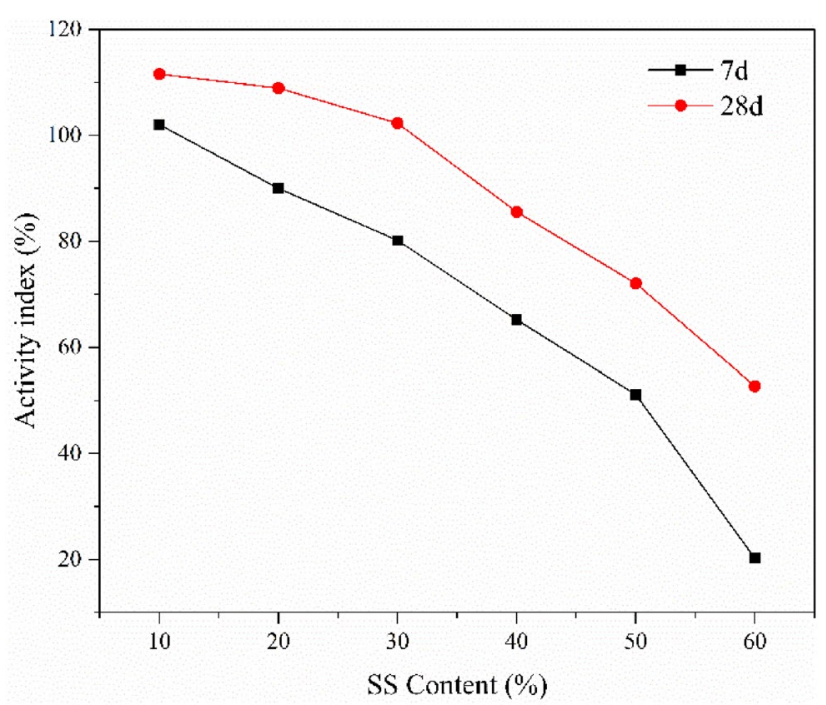

Fig. 4 Activity index of SS-C binary composites cementitious materials

strength of cement, the $28 \mathrm{~d}$ compressive strength of composite cementitious material was in the order of S16G24 $>$ S20G20 > S10 > S20 > S20G30 >S25G25 >S24G16>S30> $C$. The flexural strength of SS-GBFS-C cementitious material has a similar pattern, but the $28 \mathrm{~d}$ flexural strength of S24G16 was higher than other samples.

Among cement-based cementitious materials, SS accounts for $16 \%$ and GBFS accounts for $24 \%$, the $28 \mathrm{~d}$ 
Fig. 5 Compressive strength (a) and flexural strength (b) of SS-GBFS-C ternary cementitious materials
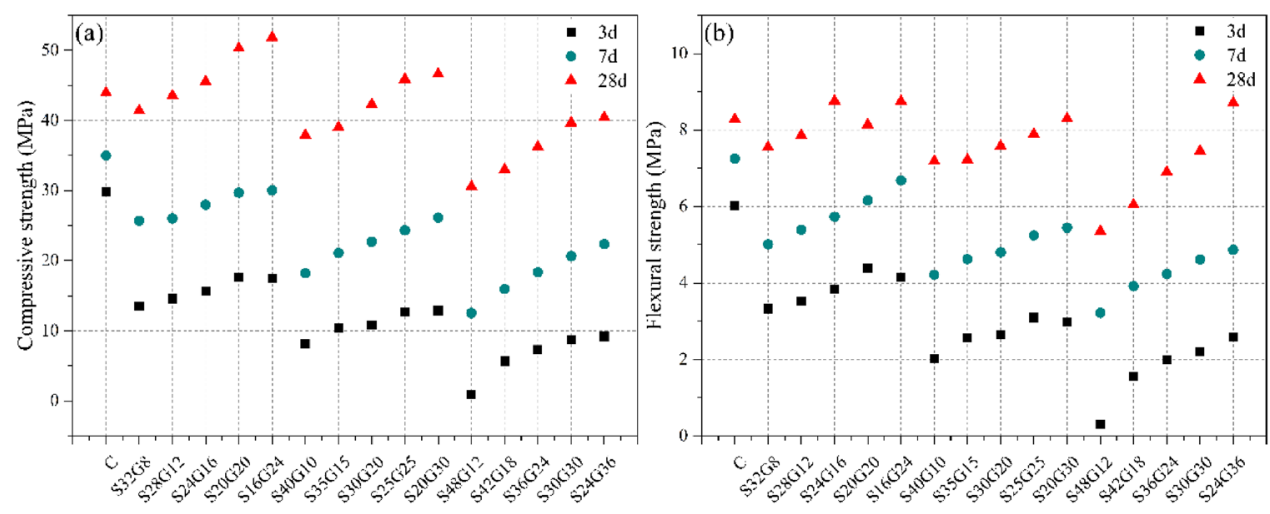

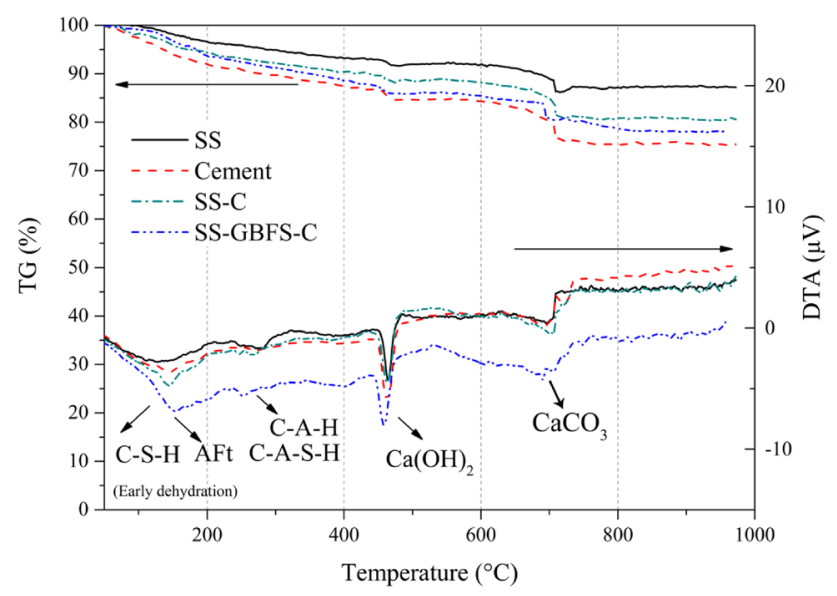

Fig. 6 TG-DTA pattern of binary and ternary cementitious materials

compressive strength of the paste reached $51.85 \mathrm{MPa}$, and its mechanical properties were far superior to pure cement (43.95 MPa). Meanwhile, the mechanical properties of ternary composite cementitious materials were generally better than that of binary composite cementitious materials, which indicated that the strength enhancement of mixing SS and GBFS was obviously stronger than that of single-doped SS.

\subsection{Thermogravimetric analysis}

Figure 6 shows the TG-DTA curve of SS-C (S50) and SS-GBFS-C (S25G25) hardened slurry hydrated for 28 days. SS-C and SS-GBFS-C hardened slurry has three obvious endothermic peak between $50^{\circ} \mathrm{C}$ and $1000^{\circ} \mathrm{C}$ as presented in DTA curve: early dehydration endothermic peak of C-S-H and AFt between 100 and $200{ }^{\circ} \mathrm{C}$, dehydration endothermic peak of $\mathrm{CH}$ between 440 and $475^{\circ} \mathrm{C}$, and decarbonation endothermic peak between 600 and $750^{\circ} \mathrm{C}$.

After 28 days of hydration, the $\mathrm{CH}$ content of binary cementitious and ternary cementitious calculated by mass loss was $12.99 \%-9.29 \%$, respectively.
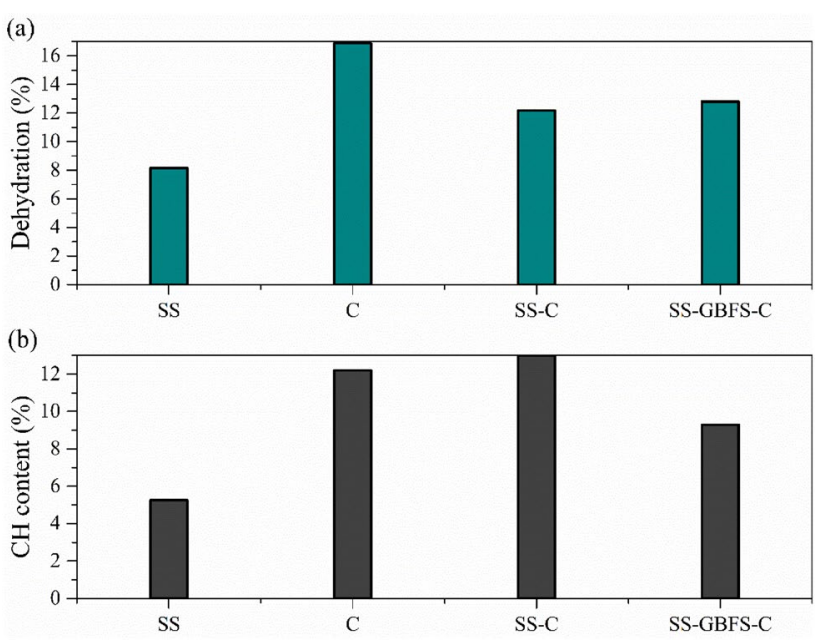

Fig. 7 Dehydration bound water content of binary and ternary cementitious materials. Content of binary and ternary cementitious materials. a Amount of dehydration of $\mathrm{C}-\mathrm{S}-\mathrm{H}$ and $\mathrm{AFt}$, b $\mathrm{CH}$ content

\subsection{The interaction of SS and GBFS in cementitious materials}

Figure 7 presents the amount of dehydration of the hydration products $\mathrm{C}-\mathrm{S}-\mathrm{H}$ and $\mathrm{AFt}$ (Fig. $7 \mathrm{a}$ ) and the $\mathrm{CH}$ content in the cementitious material after hydration (Fig. 7b). The total dehydration of $\mathrm{CSH}$ and AFt in the ternary cementitious material after hydration is higher than that of the binary cementitious material, but the overall dehydration was lower than that of pure cement.

The binary cementitious materials will produce more $\mathrm{CH}$ after hydration, while ternary cementitious materials consume $\mathrm{CH}$ due to the pozzolanic reaction of GBFS, resulting in lower $\mathrm{CH}$ content after hydration than binary cementitious materials and lower than pure cement.

GBFS has hydration activities and pozzolanic activities, which means that the $\mathrm{CH}$ was consumed and $\mathrm{C}-\mathrm{S}-\mathrm{H}$ gels were produced during its reaction process $[22,23]$. Therefore, in ternary cementitious materials, the $\mathrm{CH}$ 
produced by the hydration of SS can be provided for GBFS consumption, which participates in the pozzolanic reaction of GBFS and promotes the hydration reaction of SS. The ternary cementitious material has high strength, more dehydration of the hydration products $\mathrm{CSH}$ and $\mathrm{AFt}$, and low content of the hydration product $\mathrm{CH}$, which confirms the mutual promotion between GBFS and SS.

\section{Conclusion}

GBFS is widely used as cementitious materials to replace cement. However, the application of SS is restricted by its content in cement. In this paper, SS and GBFS were used as supplementary cementitious materials to mix cement to prepare binary and ternary cementitious materials. The main conclusions are as follows:

(1) The mineral phases in $\mathrm{SS}$ mainly contain $\mathrm{C}_{2} \mathrm{~S}, \mathrm{C}_{3} \mathrm{~S}, \mathrm{RO}$ phase, $\mathrm{C}_{2} \mathrm{~F}, \mathrm{Ca}_{2}(\mathrm{Fe}, \mathrm{Al})_{2} \mathrm{O}_{5}, \mathrm{f}-\mathrm{CaO}$ and so on. The main cementitious active substances and hydration products of SS are similar to cement.

(2) The mechanical properties of binary cementitious prepared by SS instead of cement are better than cement, but the compressive strength of binary cementitious material with SS content over 30\% decreases obviously. SS and GBFS can replace up to $50 \%$ cement, and by changing the proportion of SS and GBFS, the mechanical properties of the prepared ternary cementitious material are obviously better than cement.

(3) In the hydration process of binary and ternary cementitious materials, $\mathrm{SS}$ can produce $\mathrm{Ca}(\mathrm{OH})_{2}$ and $\mathrm{C}-\mathrm{S}-\mathrm{H}$ $\mathrm{gel}$, and the pozzolanic reaction of GBFS can consume $\mathrm{Ca}(\mathrm{OH})_{2}$ to produce more $\mathrm{C}-\mathrm{S}-\mathrm{H}$ gel. When SS and GBFS are applied together with cement-based cementitious material, they can promote each other and accelerate hydration reaction and pozzolanic reaction.

Acknowledgements This work was supported by the National Natural Science Foundation of China (Grant No. 51874013).

\section{Compliance with ethical standards}

Conflict of interest The authors declare that we have no conflict of interest.

Data availability statement All data, models or code generated or used during the study are available in a repository online in accordance with funder data retention policies.

\section{References}

1. Mo L, Zhang F, Deng M, Jin F, Altabbaa A, Wang A (2017) Accelerated carbonation and performance of concrete made with steel slag as binding materials and aggregates. Cem Concr Compos 83:138-145. https://doi.org/10.1016/j.cemconcomp 2017.07.018

2. Scrivener KL, Kirkpatrick RJ (2008) Innovation in use and research on cementitious material. Cem Concr Res 38(2):128136. https://doi.org/10.1016/j.cemconres.2007.09.025

3. Turner LK, Collins FG (2013) Carbon dioxide equivalent (CO2e) emissions: a comparison between geopolymer and OPC cement concrete. Constr Build Mater 43:125-130. https://doi. org/10.1016/j.conbuildmat.2013.01.023

4. Wang Y, He X, Su Y, Tan H, Yang J, Lan M et al (2018) Self-hydration characteristics of ground granulated blast-furnace slag (GGBFS) by wet-grinding treatment. Constr Build Mater 167:96105. https://doi.org/10.1016/j.conbuildmat.2018.01.178

5. Wang Q, Yan P, Feng J (2011) A discussion on improving hydration activity of steel slag by altering its mineral compositions. J Hazard Mater 186(2-3):1070-1075. https://doi.org/10.1016/j. jhazmat.2010.11.109

6. Yanfeng $L$ (2009) Recycling of steel slag for energy saving and its application in high performance concrete. Asia-Pacific Power Energy Eng Conf IEEE. https://doi.org/10.1109/APPEE C.2009.4918641

7. Lothenbach B, Scrivener K, Hooton RD (2011) Supplementary cementitious materials. Cem Concr Res 41(12):1244-1256. https ://doi.org/10.1016/j.cemconres.2010.12.001

8. Aprianti S, Evi. (2016) A huge number of artificial waste material can be supplementary cementitious material (SCM) for concrete production-a review part ii. J Clean Prod 142(4):4178-4194. https://doi.org/10.1016/j.jclepro.2015.12.115

9. Paris JM, Roessler JG, Ferraro CC, Deford HD, Townsend TG (2016) A review of waste products utilized as supplements to Portland cement in concrete. J Clean Prod 121:1-18. https://doi. org/10.1016/j.jclepro.2016.02.013

10. Mo KH, Johnson Alengaram U, Jumaat MZ, Yap SP, Lee SC (2016) Green concrete partially comprised of farming waste residues: a review. J Clean Prod 117:122-138. https://doi.org/10.1016/j. jclepro.2016.01.022

11. Guo X, Shi H (2013) Modification of steel slag powder by mineral admixture and chemical activators to utilize in cementbased materials. Mater Struct 46(8):1265-1273. https://doi. org/10.1617/s11527-012-9970-7

12. Wang $Q(2012)$ Influence of initial alkalinity on the hydration of steel slag. Sci China Technol Sci 55(12):3378-3387. https://doi. org/10.1007/s11431-012-4830-9

13. Han F, Zhang Z, Wang D, Yan P (2015) Hydration heat evolution and kinetics of blended cement containing steel slag at different temperatures. Thermochim Acta 605:43-51. https:// doi.org/10.1016/j.tca.2015.02.018

14. Yüksel I (2018) A review of steel slag usage in construction industry for sustainable development. Environ Dev Sustain 19(2):1-16. https://doi.org/10.1007/s10668-016-9759-x

15. Li Y, Liu Y, Gong X, Nie Z, Cui S, Wang Z et al (2015) 'Environmental impact analysis of blast furnace slag applied to ordinary Portland cement production. J Clean Prod 120:221-230. https:// doi.org/10.1016/j.jclepro.2015.12.071

16. Reddy AS, Pradhan RK, Chandra S (2006) Utilization of basic oxygen furnace (BOF) slag in the production of a hydraulic cement binder. Int J Miner Process 79(2):98-105. https://doi. org/10.1016/j.minpro.2006.01.001

17. Papayianni I, Anastasiou E (2010) Production of high-strength concrete using high volume of industrial by-products. Constr 
Build Mater 24(8):1412-1417. https://doi.org/10.1016/j.conbu ildmat.2010.01.016

18. Sheen YN, Wang HY, Sun TH (2014) Properties of green concrete containing stainless steel oxidizing slag resource materials. Constr Build Mater 50:22-27. https://doi.org/10.1016/j.conbuildma t.2013.09.017

19. Zhang T, Yu Q, Wei J, Li J, Zhang P (2011) Preparation of high performance blended cements and reclamation of iron concentrate from basic oxygen furnace steel slag. Resour Conserv Recycl 56(1):48-55. https://doi.org/10.1016/j.resconrec.2011.09.003

20. Jia R, Liu J, Jia R (2017) A study of factors that influence the hydration activity of mono-component cao and bi-component $\mathrm{CaO} / \mathrm{Ca}_{2} \mathrm{Fe}_{2} \mathrm{O}_{5}$ systems. Cem Concr Res 91:123-132. https://doi. org/10.1016/j.cemconres.2016.11.011

21. Liu J, Guo RH (2018) Applications of steel slag powder and steel slag aggregate in ultra-high performance concrete. Adv Civ Eng. https://doi.org/10.1155/2018/1426037
22. Wang YB, He XY, Su Y, Yang J, Strnadel B, Wang XJ (2019) Efficiency of wet-grinding on the mechano-chemical activation of granulated blast furnace slag (GBFS). Constr Build Mater 199:185-193. https://doi.org/10.1016/j.conbuildma t.2018.11.245

23. Mohan A, Mini KM (2018) Strength and durability studies of SCC incorporating silica fume and ultra fine GGBS. Constr Build Mater 171:919-928. https://doi.org/10.1016/j.conbuildma t.2018.03.186

Publisher's Note Springer Nature remains neutral with regard to jurisdictional claims in published maps and institutional affiliations. 